\title{
Development and Function of the Blood-Brain Barrier in the Context of Metabolic Control
}

\author{
Roberta Haddad-Tóvolli *, Nathalia R. V. Dragano, Albina F. S. Ramalho and \\ Licio A. Velloso *
}

Laboratory of Cell Signaling and Obesity and Comorbidities Research Center, Faculty of Medical Sciences, University of Campinas, Campinas, Brazil

OPEN ACCESS

Edited by:

Serge H. Luquet,

Paris Diderot University, France

Reviewed by:

Fanny V. Langlet,

University of Lille Nord de France,

France

Jacques Epelbaum

Institut National de la Santé et de la

Recherche Médicale, France

Miguel Lopez,

Universidade de Santiago de

Compostela, Spain

*Correspondence:

Roberta Haddad-Tóvoll

robshtovolli@hotmail.com

Licio A. Velloso

lavelloso.unicamp@gmail.com.br

Specialty section:

This article was submitted to Neuroendocrine Science,

a section of the journal

Frontiers in Neuroscience

Received: 15 February 2017 Accepted: 04 April 2017 Published: 21 April 2017

Citation:

Haddad-Tóvolli R, Dragano NRV, Ramalho AFS and Velloso LA (2017) Development and Function of the Blood-Brain Barrier in the Context of Metabolic Control.

Front. Neurosci. 11:224 doi: 10.3389/fnins.2017.00224
Under physiological conditions, the brain consumes over $20 \%$ of the whole body energy supply. The blood-brain barrier (BBB) allows dynamic interactions between blood capillaries and the neuronal network in order to provide an adequate control of molecules that are transported in and out of the brain. Alterations in the BBB structure and function affecting brain accessibility to nutrients and exit of toxins are found in a number of diseases, which in turn may disturb brain function and nutrient signaling. In this review we explore the major advances obtained in the understanding of the BBB development and how its structure impacts on function. Furthermore, we focus on the particularities of the barrier permeability in the hypothalamus, its role in metabolic control and the potential impact of hypothalamic BBB abnormities in metabolic related diseases.

Keywords: blood-brain barrier, neurovascular unit, development, hypothalamus, inflammation, obesity

\section{INTRODUCTION}

Blood vessels transport and deliver nutrients to warrant organism function. In the brain, they specialized into a dynamic structure that provides a protective and homeostatic interface between the central nervous system (CNS) and the remainder of the body. In this sense, the blood-brain barrier (BBB) controls the passage of selected substances into the brain, while transporting toxic products back into circulation. This efficient permeable boundary allows maintenance of the homeostasis of the CNS milieu and correct function of brain circuits.

The functionality of the BBB depends on a strict architecture. The combination of nonfenestrated brain endothelial cells (BECs) lining the walls of the CNS blood vessels, together with pericytes, neurons and glia constitute the neurovascular unit (NVU) and confer integrity to the BBB.

In the ventromedial hypothalamus, the barrier has specialized to allow the dynamic passage of hormones and nutrients from the blood to the energy-sensing arcuate nucleus of the hypothalamus (ARC) and the export of newly synthesized hormones to the pituitary. At the level of the median eminence (ME), the barrier is formed by fenestrated capillaries that allow faster transport of substances into the nutrient-sensing hypothalamic nuclei lying adjacent to it. However, ME tanycytes, specialized radial glia cells lining the walls of the third ventricle, form a physical barrier to control the correct transport of nutrients and metabolic hormones into the brain parenchyma (Weindl and Joynt, 1973; Ganong, 2000; Mullier et al., 2010; Rodríguez et al., 2010). The metabolic state, as well as the consumption of saturated fatty acids, can damage this barrier and alter the nutrient sensing of tanycytes (Lee et al., 2012; Haan et al., 2013; Langlet et al., 2013b). Changes in the development of the BBB in the hypothalamus, especially in the vicinity of the ME, may predispose to obesity (Lee et al., 2012; Kim et al., 2016). 


\section{BBB STRUCTURE AND FUNCTION}

In the last decade, there has been exponential progress in the understanding of how BBB structure and function work both in health and pathological conditions (Daneman and Prat, 2015; Banks, 2016). The first evidence for the existence of a barrier controlling the passage of substances from the circulating blood to and from the CNS dates back to 1885 when the German researcher Paul Ehrlich carried out experiments injecting Trypan Blue dye into the bloodstream of mice. Surprisingly, he noted that the dye could penetrate several tissues but not the brain and spinal cord (Ehrlich, 1885; Figure 3B). Years later, further studies performed by Goldmann (1909, 1913), Ehrlich's student, indicated that injection of the same dye directly into the brain showed the opposite as observed previously: the brains turned blue, whereas the peripheral tissues did not (Figure 3B). The term "blood-brain-barrier" was introduced by Lewandowsky (1900), based on experiments demonstrating that neurotoxic substances, e.g., cholic acids or sodium ferrocyanide, exhibited neurological symptoms only after intraventricular applications but not when injected into the bloodstream. Only in the late 1960s, with the development of electron microscopy, Reese and Karnovsky (1967) were able to visualize for the first time, at ultrastructural level, that the brain endothelial cells present unique cell-to-cell junctions, constituting a structural barrier that creates an almost impermeable frontier between the blood and CNS (Ribatti et al., 2006).

Anatomically, the BBB is comprised by a thin monolayer of BECs that are in intimate contact with vascular cells (pericytes and vascular smooth muscle cells), glial cells (astrocytes, microglia) and neurons. The crosstalk and molecular signaling between them are collectively known as the neurovascular unit (NUV) (Obermeier et al., 2013; Chow and Gu, 2015; Banks, 2016) (Figure 1). This close connection between different cells types within the NUV allows the BBB to properly perform its fundamental physiological functions.

Next, we present the main features of the cellular components of the $\mathrm{BBB}$ :

\section{Brain Endothelial Cells}

To sustain a more restrictive permeability, BECs enclose specific barrier properties, which differentiate them from peripheral endothelial cells (Andreone et al., 2015; Chow and Gu, 2015). One particular feature is the presence of junction complexes between adjacent BECs involving transmembrane proteins and multiple cytoplasmic adaptor proteins located on the apical and lateral sides of the plasma membrane.

The structural integrity of BBB is sustained mainly by tight junction (TJ) proteins and adherens junctions (AJ). Specifically, $\mathrm{TJ}$ are composed of claudin family members, occludin, junctional adhesion molecules (JAMs) and zonulae occludens (ZO-1, ZO2, and ZO-3)-membrane-associated accessory proteins that connect the cytoplasmic tails of claudins and occludin to the actin cytoskeleton to sustain the TJ structure (Luissint et al., 2012; Tietz and Engelhardt, 2015).

The primary biological role of TJs is to establish a rigorous restriction of paracellular molecular diffusion, creating a high

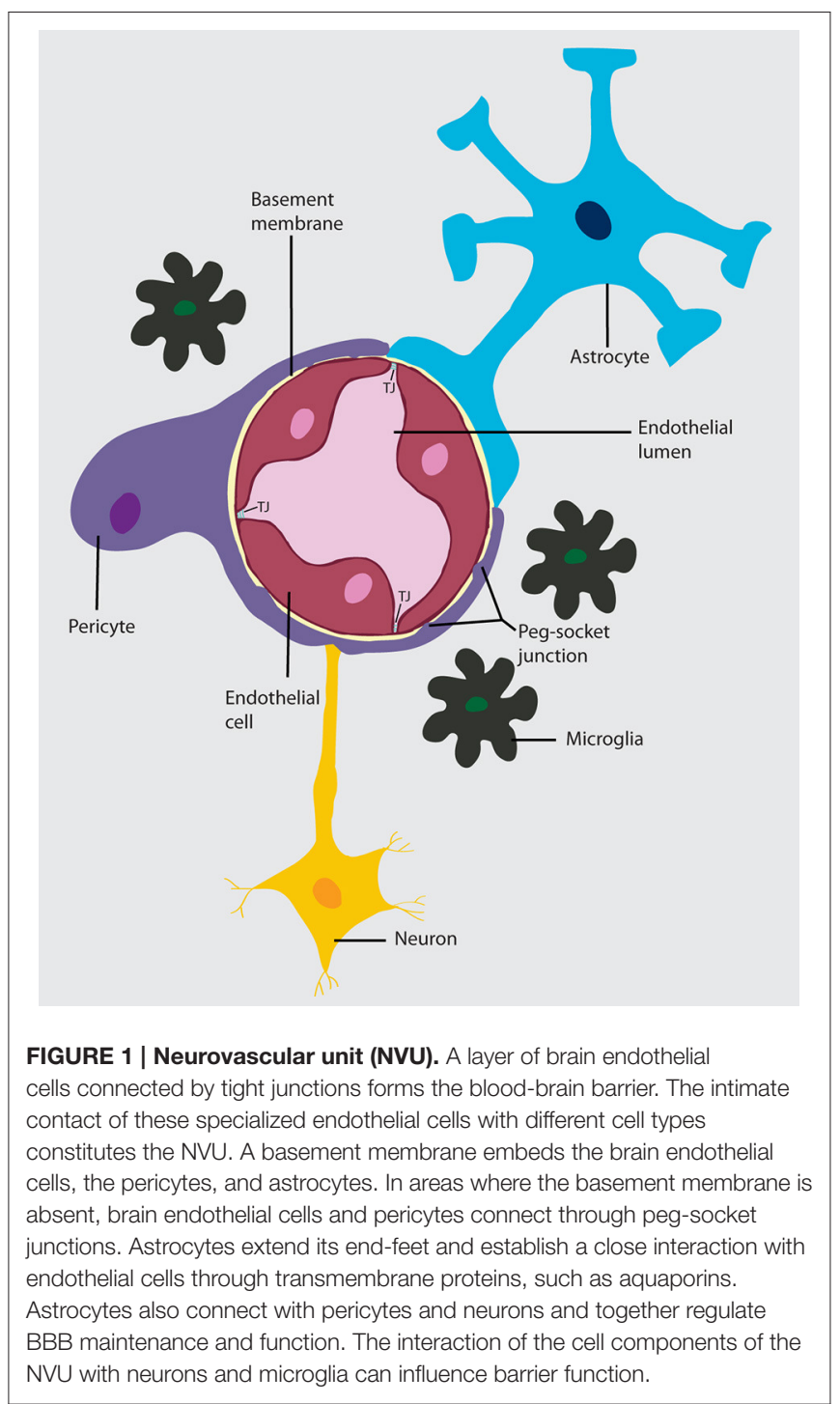

electrical resistance between the endothelial cells and ions and other polar solutes. Brain endothelial cell's AJs, ubiquitous in the vasculature, consist of cadherin proteins extended throughout the intercellular cleft that mediate cell-to-cell membrane adhesion and are anchored into the actin cytoskeleton by the scaffolding proteins alpha, beta and gamma catenin (Abbott et al., 2010; Blanchette and Daneman, 2015).

Although, the specific AJs function in the $\mathrm{BBB}$ is yet to be fully elucidated, it is known that they play an important role in the maintenance of TJs and the junctional complex by keeping the BECs together (Keaney and Campbell, 2015). In addition, brain endothelial cells display low rates of transcellular vesicular transport in comparison to peripheral endothelial cells, a process termed transcytosis (transport between the luminal and abluminal cell membranes). Still, transcytosis is the most common mechanism to selectively uptake macromolecules such as albumin, low-density lipoprotein and hormones, e.g., insulin and leptin (Holly and Perks, 2006; Xiao and Gan, 2013; Chow and $\mathrm{Gu}, 2015)$. As a result of this restrictive barrier, BECs 
express several transporters and receptor proteins, as Glut-1, that selectively allow the entry of nutrients, neurotransmitters and other essential macromolecules into the brain parenchyma, at the same time that ensure the elimination of potentially metabolic waste and neurotoxic substances from the CNS into the blood (Keller, 2013; Keaney and Campbell, 2015).

Another important feature of the BECs is the low expression levels of leukocyte adhesion molecules (LAMs) such as Eselectin and Icam1, compared with ECs in non-neuronal tissues (Andreone et al., 2015; Daneman and Prat, 2015). This characteristic greatly restrains the number of immune cells that enter the CNS. In general, the physical barrier properties mediated by the junctional complex and the reduced transcytosis along with a highly selective cellular transport system illustrates how the brain endothelium orchestrate the regulation of the brain microenvironment.

\section{Pericytes}

Pericytes were first characterized by Eberth (1871) and Rouget (1873) in the 1870's and initially named "Rouget cells." Later, Zimmermann (1923) introduced the term pericyte due to their location in close proximity to the endothelial cells. Anatomically, pericytes are located at the abluminal surface of microvessels, embedded in a common basement membrane with the BECs, and exhibit elongated cytoplasmic processes that wrap the endothelium around (Trost et al., 2016). The CNS vasculature has significantly higher pericyte density/coverage compared with peripheral tissues, which correlates with the particular endothelial barrier properties. It is estimated that the ratio of pericytes to endothelial cells in CNS is 1:1-1:3, while this ratio appears to be from $1: 10-1: 100$ in striated muscles (Shepro and Morel, 1993; Millis et al., 2013). Despite being separated by the basal membrane, in areas lacking a basement membrane (BM) BM, pericytes and BECs make direct peg-and-socket contacts, in which pericyte cytoplasmic fingers (pegs) are inserted into endothelial invaginations (pockets) (Winkler et al., 2011). Several different transmembrane junctional proteins are present at these contact points, including $\mathrm{N}$-cadherin, forming key AJs between the two cell types; connexin-43 (CX43), hemichannels that form gap junctions enabling the exchange of nutrients, secondary messengers and ions; adhesion plaques composed predominately of fibronectin that anchor pericytes to endothelial cells (Berger et al., 2005; Zlokovic, 2008; Armulik et al., 2011; Winkler et al., 2011).

Pericytes play essential roles in the regulation of several neurovascular functions. They are critical during angiogenesis, participating in vessel formation, remodeling and stabilization (see developmental section) (Armulik et al., 2011; Winkler et al., 2011). In situ and In vivo studies evidenced that pericytes are modulators of capillary diameter and blood flow in response to changes in neural activity (Peppiatt et al., 2006; FernándezKlett et al., 2010; Hall et al., 2014). However, Hill et al. (2015) demonstrate that capillary pericytes are not contractile in vivo. Thus, the active regulation of the capillary blood flow by pericytes remains controversial presumably due to the lack of proper pericyte definition and identification (Trost et al., 2016).
Apart of their importance in $\mathrm{BBB}$ development (see $\mathrm{BBB}$ development section), pericytes are involved in the formation and maintenance of the highly selected permeability of the BBB in adulthood and aging (Armulik et al., 2010; Bell et al., 2010; Daneman et al., 2010a). Pericyte deficiency promotes severe BBB dysfunction as a result of increased vascular permeability (directly correlated with absolute pericyte coverage, increased rates of transcytosis and paracellular transport due to reduced expression of various TJ and AJ proteins). Pericytes also guide astrocytic foot processes to surrounding CNS blood vessels and mediate the polarization of astrocytic end-feet, highlighting the interdependence among components of the NVU (Armulik et al., 2010; Keaney and Campbell, 2015).

Increasing evidence has shown that pericytes may constitute multipotent stem/progenitor cells that could differentiate into mesenchymal cells and into non-mesenchymal cell types, including glial and neuronal lineages under different in vitro conditions (Bribair et al., 2013). Until now, there is still a lack of studies describing that such differentiation occurs in the brain (Dore-Duffy and Cleary, 2011; Trost et al., 2016). Moreover, pericytes can control several aspects of the CNS immune response (reviewed in Rustenhoven et al., 2016).

\section{Astrocytes}

Due to the position of astrocytes in the NUV (ensheathing almost $90 \%$ of brain microvasculature), many studies have focused on the role of astrocytes in the maturation and maintenance of BBB (Correale and Villa, 2009). Indeed, astrocytes can induce barrier properties in non-CNS endothelial cells in vivo (Janzer and Raff, 1987).

Astrocytes, the most abundant cells in the brain, are spongiform-shaped glial cells that extend many branching cellular processes, including astrocytic end-feet that cover brain endothelial cells. Specifically, astrocytic end-feets establish a close interaction with BECs through transmembrane proteins anchoring, such as the water channel Aquaporin-4 (Aqp4) and the potassium channel KIR4.1, critical for CNS water homeostasis regulation (Cabezas et al., 2014). Furthermore, astrocytes communicate between each other through gap junctions forming an extensive glial syncytium that is associated with well-coordinated responses within large groups of cells (Theis et al., 2005; Alvarez et al., 2013). Astrocytes perform several functions critical to CNS physiology, including the regulation of blood flow in response to changes in neuronal activity which results in enhanced delivery of oxygen and glucose to the active brain region; the maintenance of ion and neurotransmitters concentration within the extracellular space for proper synaptic transmission; the modulation of synaptic and neural activity by the release of gliotransmitters, such as glutamate, ATP, D-serine, and GABA; and are also able to respond to local levels of nutrients, glucose uptake from blood vessels and the storage of glycogen, which is hydrolyzed to release lactate into the extracellular space when glucose is scarce (Sofroniew and Vinters, 2010; Cabezas et al., 2014).

One of the essential roles attributed to astrocytes is to regulate the nutrient availability, such as glucose, and also the access of some peripheral hormones, including leptin, ghrelin and GLP-1. 
Their privileged anatomical position, in close proximity to the blood vessels and neurons, allows them to act as important metabolic sensors. Actually, hypothalamic astrocytes express specific transporters and receptors that are involved in the control of energy homeostasis. The astrocytic end-feet that enclose capillaries express the glucose transporter GLUT-1 that transports glucose into the CNS. The uptaken glucose is stored in form of glycogen, which is mobilized to release lactate to the neurons when glucose is not abundant, as in periods of energy deficit (Argente-Arizón et al., 2015; Chowen et al., 2016). Astrocytes also express the glucose transporter GLUT-2 that is important for glucosensing process and in the homeostatic control of circulating glucose levels and food intake (Marty et al., 2005; Stolarczyk et al., 2010). GLUT-2 inactivation results in overeating, providing evidence that glucose detection by GLUT2 contributes to the control of food intake by the hypothalamus (Bady et al., 2006; Stolarczyk et al., 2010). Leptin receptors are expressed in hypothalamic astrocytes and their physiological relevance was recently demonstrated. The conditional deletion of the leptin receptor in GFAP positive cells in mice decreased the number and length of astrocyte projections in hypothalamic neurons involved in feeding control, such as POMC and AGRP neurons of the arcuate nucleus. In addition, leptin-regulated feeding was diminished in mice with astrocyte-specific leptin receptor deficiency (Kim et al., 2014).

Regarding the contribution of astrocytes in BBB development, they do not appear to participate in this process at early embryonic stages (see development section) (Daneman et al., 2010 b). Indeed, mature astrocytes produce factors that regulate $\mathrm{BBB}$ function and integrity. Astrocytes also secrete angiopoietin1 and angiotensin that restrict $\mathrm{BBB}$ permeability by supporting efficient organization of TJs (Lee et al., 2003; Wosik et al., 2007; Siegenthaler et al., 2013). Thus, astrocytes are critical in sustaining $\mathrm{BBB}$ functionality and integrity as well as in the regulation of neuronal and synaptic activity.

\section{Microglia}

In addition to pericytes and astrocytes, the brain endothelium at the NUV is in close contact with immune cells. The two main immune cell populations within the CNS are perivascular macrophages and microglia.

Perivascular macrophages are monocytic lineage cells located outside of the CNS parenchyma. In fact, these cells reside in and circulate through the Virchow-Robin spaces, which lie between the $\mathrm{BM}$ around pericytes and at the surface of the glia interface of the brain vessels. The perivascular macrophage number is continuously maintained by replacement from blood-borne cells macrophages. They provide a first line of innate immunity due to their ability to quickly phagocytose particles from the cerebrospinal fluid (Daneman and Prat, 2015).

The brain parenchyma is populated by microglia, the most abundant CNS innate immune cells. Microglial cells, also referred as resident macrophages of the brain, are derived from progenitors in the yolk sac, which migrate into the CNS parenchyma during neonatal development. Microglia colonization comes first during BECs invasion into the brain (da Fonseca et al., 2014) and are shown to be involved in CNS vasculogenesis, promoting endothelial cell fusion to increase vascular complexity (Fantin et al., 2010), as well as decreasing paracellular permeability in cultured BECs (Zenker et al., 2003). Accordingly, these data suggest that the interactions between microglia and the brain endothelium could participate in the BBB formation and regulation (Correale and Villa, 2009; da Fonseca et al., 2014).

Generally, microglia displays two distinct morphological patterns. The steady-state population of microglia in the healthy brain exhibits a 'resting' phenotype, which is characterized by a small, and circular cell body with extensively ramified processes. As a part of their homeostatic functions, microglial cell bodies remain stationary, but their processes continuously scan the surrounding extracellular space and communicate directly with neurons, astrocytes, and blood vessels (Nayak et al., 2014). Microglia rapidly respond to injury signals or infection through an activated phenotype characterized by a morphological change into an amoeboid shape and alterations in signaling and gene expression in order to perform inflammatory functions (Lull and Block, 2010; Saijo and Glass, 2011).

Prolonged microglia activation and consequent chronic neuroinflammatory state in CNS might induce impairments in $\mathrm{BBB}$ integrity that, in turn, contribute to the progression of neurodegenerative diseases (reviewed in de Vries et al., 2012). Evidence from in vitro studies has shown that microglia activation may be related to $\mathrm{BBB}$ disruption. Sumi et al. (2010) demonstrated that the treatment of a rat brain microvascular endothelial cell/microglia co-culture system with lipopolysaccharide, a microglial activator, induced an increase in endothelial cell permeability and changes in the expression pattern of tight junction proteins. Another study using a similar in vitro co-culture system found that the tumoral necrosis factor $\alpha$ (TNF- $\alpha)$ released from activated microglia also increased the permeability of BECs, which could be blocked by a neutralizing antibody against TNF- $\alpha$ (Nishioku et al., 2010).

Although, these in vitro $\mathrm{BBB}$ models are important for unraveling the mechanisms involved in the crosstalk between microglia activation and BBB integrity, more studies are needed to improve our understanding on how these cell types interact in vivo.

\section{BBB DEVELOPMENT}

The development and differentiation of the BBB can be subdivided into three phases: i, angiogenesis; ii, differentiation; and iii, maturation (summarized in Figure 2).

The angiogenic phase begins early during neural tube development (as early as E9.0-E10.5 in mice). Endothelial cells from the perineural vascular plexus penetrate the neuroectoderm according to a vascular endothelial growth factor (VEGF) concentration gradient giving rise to immature brain vessels (Raab et al., 2004; Potente et al., 2011). VEGF is expressed by the neural progenitors of the ventricular neuroepithelium and serves, together with angiopoietin, as a major driving force for the migrating endothelial cells (EC) (Risau et al., 1986). VEGF deficiency is lethal (Shalaby et al., 1995; Carmeliet et al., 1996). 

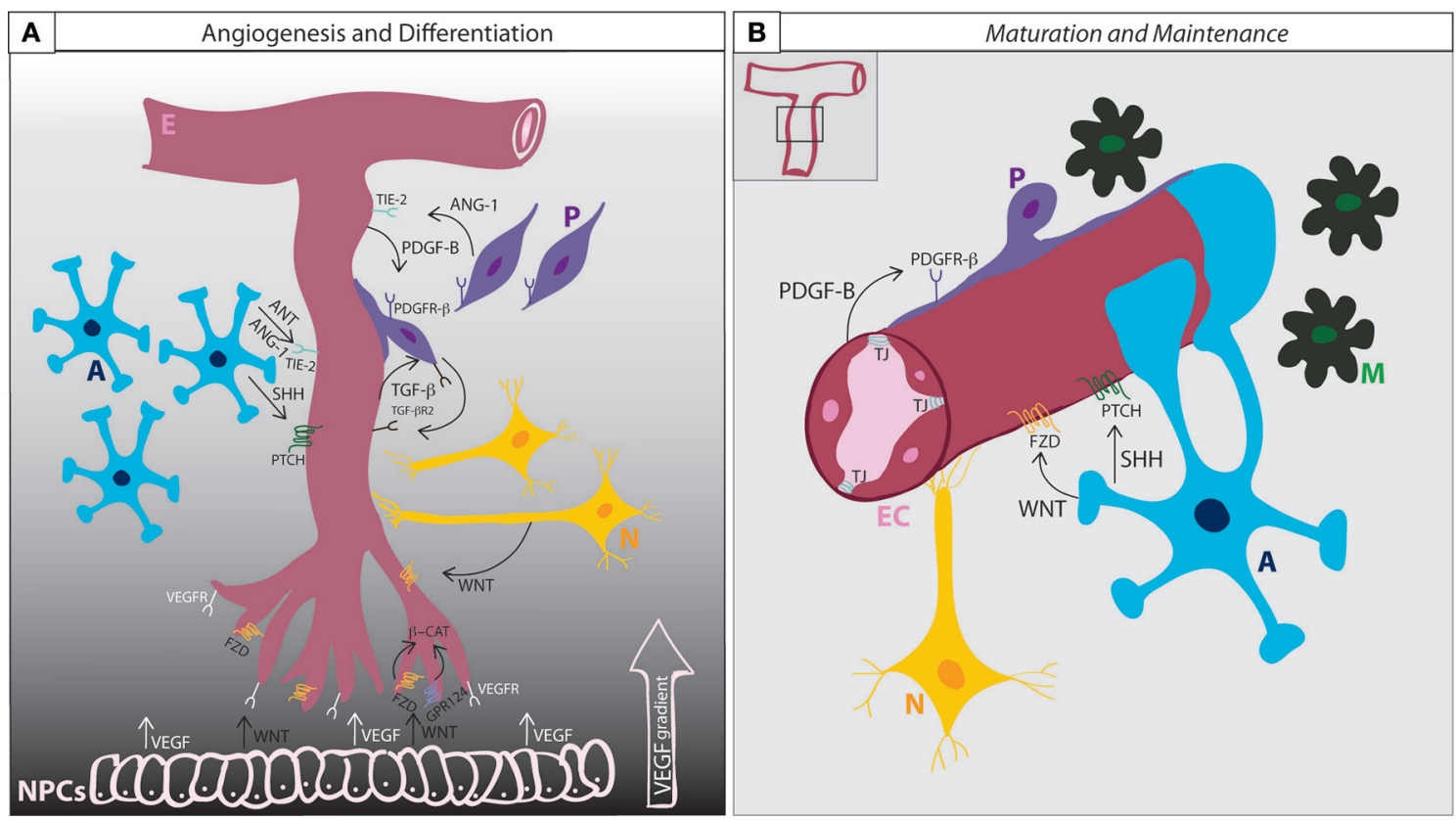

FIGURE 2 | BBB development and maintenance. (A) Angiogenesis and differentiation. VEGF secretion from neural progenitor cells induces endothelial cells penetration into the brain parenchyma according to a VEGF concentration gradient. Wnt ligands also secreted from the NPCs induces the migration of the endothelial cells and activate $\beta$-catenin signaling through the binding to Frizzled receptors, inducing the expression of BBB specific genes. GPR124, together with WNT, co-activates $\beta$-catenin signaling. Endothelial cells secrete PDGF-B and attract pericytes expressing PDGFR- $\beta$. The interaction between ECs and Ps induce the mutual expression of TGF- $\beta$ and TGF- $\beta$ R2. The activation of TGF- $\beta$ signaling regulates basement membrane formation and the induction of Ang- 1 expression in pericytes, that acting through the endothelial receptor Tie-2, enhance tight junction expression. Astrocytes release $\mathrm{SH}$, that when bound to PTCH receptor induces Shh signaling activation in ECs and contributes to BBB formation. Astrocytes also express ANT and ANG-1, which by limiting BBB permeability contributes to the maturation of BBB function. (B) Maturation and Maintenance. Pericytes and astrocytic end-feet cover the endothelium and secrete matrix proteins that will constitute the basement membrane. Astrocytes continue secreting SHH and WNT in order to maintain BBB functionality throughout life. A, astrocytes; E, endothelium; EC, endothelial cell; M, microglia; N, neuron; NPC, neural progenitor cell; P, pericyte; TJ, tight junction; Ang-1, angiopoietin-1; ANT, angiotensin; $\beta$-cat, beta-catenin; VEGF, vascular endothelial growth factor; VEGFR, vascular endothelial growth factor receptor; FZD, frizzled; GPR124, adhesion G protein coupled receptor A2; Shh, sonic hedgehog; Ptch, Patched 1; PDGF-B, platelet derived growth factor B; PDGFR- $\beta$, platelet derived growth factor receptor beta; TGF- $\beta$, transforming growth factor-beta; TGF- $\beta$ R2, transforming growth factor beta receptor type-2.

Downstream VEGF signaling supports angiogenesis through endothelial cell proliferation, migration and survival (Olsson et al., 2006). Together with VEGF, neural Wnt signaling plays an important role in the development of the BBB (Daneman et al., 2009). Different Wnt ligands, including Wnt7a, Wnt7b, and Wnt3a are secreted by the neuroepithelium (Wang et al., 2012) and induce further ingression of ECs into the neural tissue, activating Wnt/B-catenin signaling in the newborn endothelial cells (Liebner et al., 2008; Daneman et al., 2009; Zhou and Nathans, 2014) that leads to induction of genes critical for the $\mathrm{BBB}$ formation and vascular patterning, such as glucose transporter Glut-1 (Stenman et al., 2008), death receptors DR6 and TROY (Tam et al., 2012) and tight junction proteins. Defects in $W n t / \beta$-catenin signaling result in major vascular malformations and BBB breakdown (Stenman et al., 2008; Daneman et al., 2009; Wang et al., 2012). Retinoic acid, Notch signaling receptor tyrosine kinase, cadherins and ephrins also contribute to angiogenesis in the CNS (Adams and Alitalo, 2007; Dejana and Vestweber, 2013).

At about E15.5, the newly formed vessels continue to differentiate and mature as a complete NVU forming the basis for the BBB. During the differentiation phase (between E15.5 and E18.5 in mice), the brain barrier is structured properly by the induction of anti-angiogenic signals and the recruitment of pericytes and astrocytes to the newly formed vessels. Pericytes express the platelet-derived growth factor receptor- $\beta$ (Pdgfr- $\beta$ ) and are directed to the endothelial developing capillaries that secrete Pdgf-B (Lindahl et al., 1997; Hellstrom et al., 1999). Pdgfr- $\beta$ mouse mutants completely lack brain pericytes, and die as consequence of brain microhemorrhages (Lindahl et al., 1997; Lindblom et al., 2003; Tallquist et al., 2003); thus, pericyte recruitment to the developing endothelial capillaries is critical for the formation and maintenance of the BBB (Armulik et al., 2010; Bell et al., 2010; Daneman et al., 2010a). The lack of Pdgf- $\beta$ or Pdgfr- $\beta$ leads to erroneous TJ distribution and increased vascular permeability (Hellstrom et al., 2001).

Interactions between pericytes and the brain endothelial cells lead to the expression of transforming growth factor- $\beta$ (Tgf- $\beta$ ) and its receptor (Tgf- $\beta$ R2) by both cell types. TGF secretion induces cell adhesion through the production of cadherin-2 by the endothelial cells and the secretion of different extracellular matrix components that contribute to basement membrane (BM) 
formation by the pericytes (Winkler et al., 2011). Notch and sphingosine-1-phosphate (S1P) signaling also contribute to the regulation of cadherin-2 expression in BECs (Winkler et al., 2011; Obermeier et al., 2013). Upon activation of Tgf- $\beta$ signaling, pericytes produce Ang-1 that, by enhancing tight junctions formation, limit BBB permeability, and reduce the expression of leukocyte adhesion molecules (LAMs). Pdgf- $\beta$ and Wnt $/ \beta$ catenin signaling is also important during the differentiation of the $\mathrm{BBB}$ by the induction of transporters and increased expression of tight junctions. This provides integrity to the barrier (Liebner et al., 2008; Daneman et al., 2009; Tam et al., 2012; Wang et al., 2012; Zhou and Nathans, 2014; Andreone et al., 2015). In the BBB, Gpr124 has been described as a necessary endothelial receptor specifically in the CNS and function as a coactivator of Wnt/b-catenin signaling to mature the BBB (Kuhnert et al., 2010; Cullen et al., 2011; Zhou and Nathans, 2014).

Pericytes are apparently required to guide astrocytes toward the developing BBB (Armulik et al., 2010). Once recruited to the forming $\mathrm{NVU}$, astrocytes are involved in limiting $\mathrm{BBB}$ permeability by the release of Sonic Hedgehog (Shh). The activation of Shh signaling leads to the expression of occludin and claudin 5 and inhibition of chemokines and cell adhesion molecules in the endothelial cells, suggesting a role for astrocytes and Shh in maintenance of BBB functionality and immune surveillance (Alvarez et al., 2011; Obermeier et al., 2013; Siegenthaler et al., 2013). Recent studies have uncovered yet another important role for astrocytes in the production of retinoic acid, which is also necessary for the correct development of BBB vessels (Halilagic et al., 2007; Mizee et al., 2013).

Maturation and maintenance of the $\mathrm{BBB}$ is achieved by the persistence of tight junction proteins expression and their redistribution throughout the whole $\mathrm{BBB}$ structure. The production of TJs is regulated by Wnt signaling between astrocytes and BECs. Close contact between the endothelial cells, pericytes, astrocytes, and possibly neurons and microglia sustain $\mathrm{BBB}$ integrity and function as a stabilized neurovascular unit (reviewed in Obermeier et al., 2013; reviewed in Engelhardt and Liebner, 2014; reviewed in Zhao et al., 2015). The BBB is already formed and completely functional during late gestation in rodents and in the third trimester in humans (Bauer et al., 1995; Daneman et al., 2010a; Ben-Zvi et al., 2014). In the rat embryo, the BBB is already functional at E16 (Saunders et al., 2012). The exact time window remains elusive and is likely species dependent (Saunders et al., 2013; Hagan and Ben-Zvi, 2015).

There has been intense debate on the BBB features that provide its correct function. To date, it is believed that tight junctions are functional in sealing the space between BBB endothelial cells very early in development (Dziegielewska et al., 1979; Bondjers et al., 2006; Tam et al., 2012; Ben-Zvi et al., 2014) but only when the intracellular pathway of transcytosis is partially downregulated will the complete restrictive properties of the barrier become fully matured (Hagan and Ben-Zvi, 2015). Little is known about the functionality of transporters at the embryonic $\mathrm{BBB}$, although some transporters, like Glut-1, are known to be expressed very early (Boado and Pardridge, 1990; Farrell and Pardridge, 1991; Bauer et al., 1995; Hagan and BenZvi, 2015). A role of Mfsd2a in participating in the inhibition of vesicular trafficking and inducing a more sealed barrier during development was suggested recently (Ben-Zvi et al., 2014; reviewed in Hagan and Ben-Zvi, 2015). Mfsd2a mutants have a defective $\mathrm{BBB}$ even though presenting proper and functional tight junctions (Ben-Zvi et al., 2014). Thus, barrier transporting properties would be determined very early in development while the sealing function would be acquired gradually across development, first with the suppression of fenestrations, then with the appearance of functional TJs, and finally with the decrease of transcytosis by the expression of Mfsd2 (Ben-Zvi et al., 2014; Hagan and Ben-Zvi, 2015).

Alterations in barrier development and in TJ expression could lead to anomalies later in life as well as to increased predisposition to develop metabolic diseases. Maternal obesity increases BBB permeability in the offspring (Kim et al., 2016), leading to higher exposure to leptin and ghrelin. In consistence with that, overnutrition during early postnatal life alters brain sensitivity to ghrelin (Collden et al., 2014), suggesting that nutrient sensing control alterations during specific hypothalamic developmental time-points could contribute to metabolic defects in the adult life. These alterations can affect the programming of energy homeostasis circuits predisposing the offspring to the development of metabolic syndrome at early life and/or adulthood.

\section{BBB IN THE HYPOTHALAMIC AREA}

In some areas of the brain, the BBB is modified in order to allow the access of certain substances from systemic circulation into the central nervous system. This occurs particularly in periventricular areas creating a blood/spinal fluid interface (Bennett et al., 2009). In these regions, the BBB capillaries are highly fenestrated with less tight junctions between endothelial cells creating a more permeable barrier (Bennett et al., 2009). Seven periventricular regions display differential barrier properties and are collectively known as the circumventricular organs: i, sub-fornical organ; ii, organum vasculosum of the lamina terminalis; iii, pituitary; iv, area postrema; v, median eminence (ME); vi, subcomissural organ; and vii, pineal (Bennett et al., 2009; Szathmari et al., 2013). In these regions, in addition to the cells that classically form the BBB vessels, a differential type of radial glial cell, termed tanycytes are also found in the interface between the spinal fluid and the capillaries (Rodríguez et al., 2010). Because of its physical proximity with the hypothalamus, the $\mathrm{BBB}$ at the $\mathrm{ME}$ is of particular interest regarding whole-body energy homeostasis and metabolism.

The median eminence is adjacent to the arcuate nucleus (ARC) of the hypothalamus. This region harbors neurons that play important roles in the control of whole body metabolism (Velloso and Schwartz, 2011; Cavadas et al., 2016). Classically, two main neuronal populations control energy homeostasis in the ARC: i, NPY/AgRP neurons, which are active during fasting and provide orexigenic and anti-thermogenic signals; ii, POMC/CART neurons, which are active following food intake and provide anorexigenic and pro-thermogenic signals (Velloso and Schwartz, 2011; Cavadas et al., 2016). In addition, 


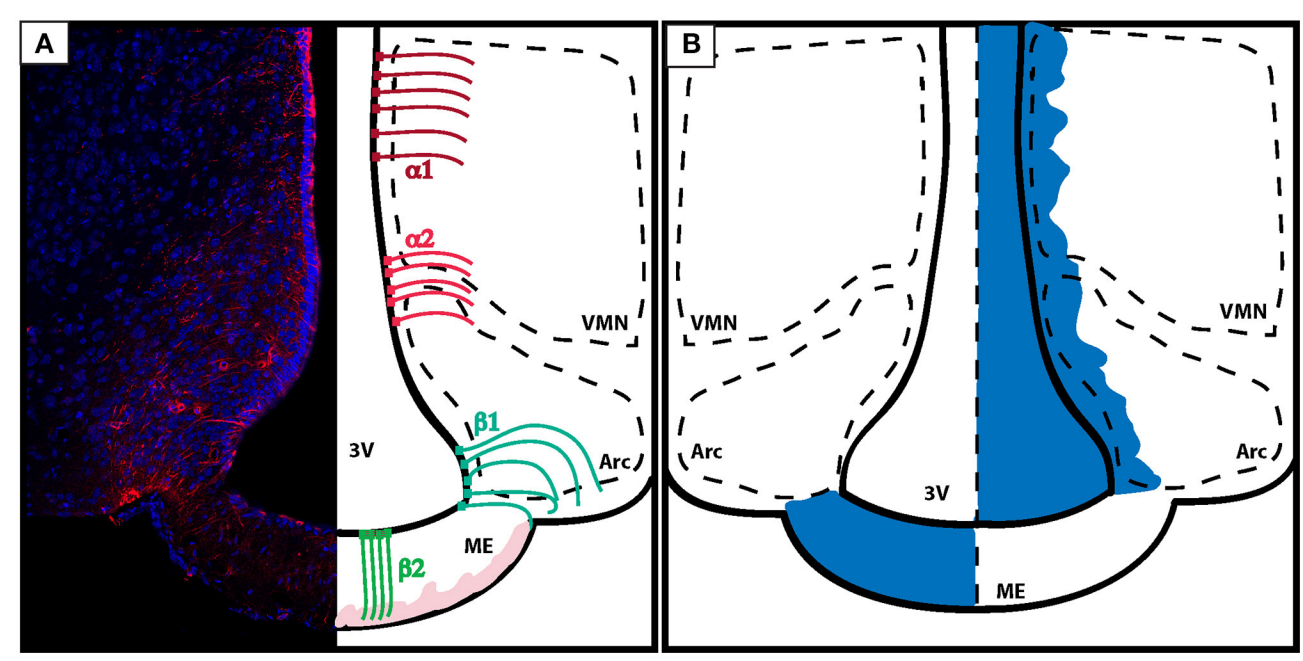

FIGURE 3 | Organization of the BBB in the energy-sensing hypothalamus. (A) Coronal section of the tuberal hypothalamus showing the distribution of tanycytes along the third ventricle wall. Left: vimentin staining (red) shows the projections of tanycytes to the brain parenchyma. Right: tanycytes line the third ventricle and can be classified according to location and function. $\alpha$ tanycytes don't possess barrier properties. $\alpha 1$ tanycytes (dark red) lye in the dorsal ventro-medial nucleus of the hypothalamus, while $\alpha 2$ tanycytes (light red) are found in between the ARC and the VMH. $\beta$ tanycytes are located ventrally and function as gatekeeper cells controlling the passage of substances from the leaky ME to the ARC. $\beta 1$ tanycytes (turquose) divide the ME from the ARC, while $\beta 2$ tanycytes (green) are located in the $\mathrm{ME}$, and characterized by processes with direct access to the blood capillaries. Blood capillaries are displayed in light pink. (B) Diagram showing how the diffusion of dyes injected peripherally do not penetrate the brain (exemplified here by the action of tanycytes lining the ME and the ARC) (left). On the other hand, dyes that are infused inside of the brain ventricles diffuse trhough the CSF and penetrate the brain parenchyma but do not pass the ME in the direction of the portal capillaries (right). VMN, ventro-medial nucleus; ARC, arcuate nucleus; ME, median eminence; 3V, third ventricle.

other distinct hypothalamic neuronal subpopulations have been described recently (Zhang and van den Pol, 2016; Campbell et al., 2017; Fenselau et al., 2017; Lam et al., 2017). Of note, a recent study has identified ARC neurons that express the dopaminesynthesizing enzyme, tyrosine hydroxylase $(\mathrm{TH})$. These cells are involved in the integration of homeostatic and hedonic feeding signals and are potential targets for the treatment of obesity (Zhang and van den Pol, 2016).

Because ARC neurons are involved in the sensing of the nutritional status of the body, it would be expected that they were located in an anatomical area where the access to nutrients and energy-status signaling substances would be facilitated. In fact, studies have shown that the interface between the median eminence and the ARC is somewhat leaky to hormones and nutrients (Obici and Rossetti, 2003; Lam et al., 2005). For example, fatty acids present in the systemic circulation are not freely diffusible to most areas of the CNS (Mitchell and Hatch, 2011). In general, they rely on particular transport systems present in the structures of the BBB (Betsholtz, 2014). The proper function and distribution of these transport systems is of major importance in the development and physiology of the brain throughout life because most fatty acids that comprise the central nervous system phospholipids cannot be synthesized de novo in the brain, and thus, must be obtained from the systemic circulation (Mitchell and Hatch, 2011). However, in the ME specific conditions make circulating fatty acids more available to ARC neurons (Obici and Rossetti, 2003; Lam et al., 2005).

As early as the 1970's, studies have revealed that hormones involved in energy homeostasis and nutrients have particular properties to cross the BBB at the ME/ARC interface. Systemic insulin crosses the $\mathrm{BBB}$ by a saturable system (Woods and Porte, 1977) and concentrates mostly in the olfactory bulb and hypothalamus (Havrankova et al., 1981). Similarly, leptin reaches the brain by a saturable system, which is independent of insulin and is highly detectable in the choroid plexus, the ME and the ARC (Banks et al., 1996). A major advance in understanding how hypothalamic neurons are exposed to hormones and nutrients to respond to systemic variations in whole body energy status was obtained by the characterization of the presence of nutrient transporters in BBB endothelial cells. Beginning in the 1990's a series of studies have explored the particularities of how peptides can cross the BBB (Cashion et al., 1996; Pam et al., 1996; Banks et al., 1997). The BBB endothelial cells are also provided with transport systems for glucose (Pardridge et al., 1990); fatty acids (Obici and Rossetti, 2003; Lam et al., 2005) and aminoacids (Hawkins et al., 2006), and the variations in whole body energy status, such as in fasting/feeding or metabolic diseases can affect function of such transport systems (Kastin and Akerstrom, 2000; Kastin et al., 2001). This implies that the BBB at the ME/ARC interface plays a major role in controlling the way hypothalamic neurons are exposed to systemic factors involved in metabolism and nutrition. In this context, important advance in the field by exploring the mechanism involved in the regulation of the ME tanycytes has been provided over the last few years.

Tanycytes are originated from the radial bipolar glia around E17.5 in mice and have a morphology that is somewhere in between the aspects of an ependymal cell and an astrocyte; differing from the last by having a single basal projection directed 
toward the parenchyma of the brain (Rodríguez et al., 2010; Figure 3A).

Mounting evidence suggests that, at least part of the selective leakiness of the $\mathrm{BBB}$ at the median eminence relies on the responsiveness of tanycytes to nutrients present in the bloodstream. Early studies evaluating hypothalamic tanycytes have demonstrated their role in the transport of substances between the third ventricle and ME (Wagner and Pilgrim, 1974). Also, tanycytes were shown to respond to hormone production and direct hormone delivery to certain anatomical sites and systemic circulation (Akmayev and Popov, 1977; Vallet et al., 1991). Interestingly, tanycytes respond rapidly to systemic stimulation, suggesting that this particular cell-type could play a role in the dynamic control of median eminence and adjacent areas exposure to systemic factors (Lichtensteiger et al., 1978). Recent studies have provided important progress in the understanding of the roles played by tanycytes in the ME and ARC (Langlet et al., 2013a,b).

The identification of leptin in the mid 1990's placed the ARC in the center of a complex system that controls body energy status (Zhang et al., 1994). With this concept in mind, researchers looked for a potential involvement of $\mathrm{ME}$ tanycytes as gatekeepers controlling the access of substances (particularly nutrients and hormones) that could modulate ARC-neuron function. However, it was only in 2011 that first evidence was provided showing that tanycytes are responsive to glucose fluctuations promoted by feeding (Frayling et al., 2011). Glucose leads to a powerful ATP-mediated $\mathrm{Ca}^{2+}$ release into the tanycytes, which in turn release ATP to adjacent cells. Therefore, it was proposed that by responding to glucose and releasing ATP, ME tanycytes could modulate the activity of ARC neurons (Frayling et al., 2011). Furthermore, ME tanycytes can transport leptin into the mediobasal hypothalamus (Balland et al., 2014). When leptin present in the bloodstream reaches the median eminence it activates leptin receptors expressed in the tanycytes. This in turn, activates the protein ERK that transduces the signals required for an appropriate transport of leptin through the cerebrospinal fluid into the ARC (Balland et al., 2014).

Interestingly, in order to respond to the constant changes in nutrient and hormone availability in the circulation, the plasticity of the median eminence tanycytes has proven remarkable. During the physiological cycles of fasting and feeding these cells undergo both morphological and functional changes (Langlet et al., 2013a). The decreased blood levels of glucose during fasting are capable of inducing changes in the structure of the interface between the blood and the ARC. At least in part, these morphological and functional changes are dependent of the expression of VEGF-A by the tanycytes (Langlet et al., 2013a).

In addition to glucose and leptin, fatty acids can also affect ME tanycytes. In diet-induced obesity, the amount of lipid

\section{REFERENCES}

Abbott, N. J., Patabendige, A. A., Dolman, D. E., Yusof, S. R., and Begley, D. J. (2010). Structure and function of the blood-brain barrier. Neurobiol. Dis. 37, 13-25. doi: 10.1016/j.nbd.2009.07.030 droplets increase considerably in tanycytes (Hofmann et al., 2017). Moreover, the ratio between saturated and unsaturated lipids is modified suggesting that this cell type may also act as a sensor and gatekeeper for lipids in the median eminence/ARC interface (Hofmann et al., 2017).

\section{CONCLUDING REMARKS}

The $\mathrm{BBB}$ provides a physiological interface between the central nervous system and the systemic circulation allowing the entrance of nutrients and certain signaling molecules and restraining the entrance of microorganisms and particles that can harm the brain. Because hypothalamic neurons must sense the energy status of the body, the BBB at the median eminence specialized to a more permeable interface between the vasculature and the brain. Recent studies have demonstrated that tanycytes present in the interface between the ARC and the median eminence are very sensitive to nutrients. They can be rapidly modified in response to fast and fed states and also, can be disturbed by abnormal consumption of nutrients derived from the diet. In obesity and in metabolic conditions associated with the obese phenotype, hypothalamic neurons are affected by a local inflammatory response that is triggered by the excessive amount of fatty acids in the diet. Mounting evidence suggest that, at least in part, the anomalous activity of the hypothalamic tanycytes can play a role in the defective neuronal activity in obesity and associated conditions. Future studies should focus on the identification of mechanisms that may protect the tanycytes from diet-induced abnormalities and the impact of such protection in the progression of metabolic diseases.

\section{AUTHOR CONTRIBUTIONS}

RHT, NRVD, and LAV discussed the structure of the manuscript. NRVD wrote the aspects of the BBB structure and function and RHT wrote the developmental topic. LAV and AFSR wrote BBB specialization in the hypothalamus. RHT, NRVD, and LAV wrote the introduction, abstract, and conclusion remarks. RHT made the figures and figure legends.

\section{ACKNOWLEDGMENTS}

The writing of this article was supported by São Paulo Research Foundation (2013/07607-8 and 2015/50278-0). Funding was provided by São Paulo Research Foundation as postdoctoral fellowships to RHT (2015/02913-9 and 2016/01868-2) and NRVD (2014/26942-5). The Laboratory of Cell Signaling belongs to the Obesity and Comorbidities Research Center and the National Institute of Science and Technology-Diabetes and Obesity.

Adams, R. H., and Alitalo, K. (2007). Molecular regulation of angiogenesis and lymphangiogenesis. Nat. Rev. Mol. Cell Biol. 8, 464-478. doi: 10.1038/ nrm2183

Akmayev, I. G., and Popov, A. P. (1977). Morphological aspects of the hypothalamic-hypophyseal system, VII The tanycytes: their relation to the 
hypophyseal adrenocorticotrophic function, An ultrastructural study. Cell Tissue Res. 180, 263-282. doi: 10.1007/bf00231958

Alvarez, J. I., Dodelet-Devillers, A., Kebir, H., Ifergan, I., Fabre, P. J., Terouz, S., Sabbagh, M., et al. (2011). The Hedgehog pathway promotes bloodbrain barrier integrity and CNS immune quiescence. Science 334, 1727-1731. doi: 10.1126/science.1206936

Alvarez, J. I., Katayama, T., and Prat, A. (2013). Glial influence on the blood brain barrier. Glia 61, 1939-1958. doi: 10.1002/glia.22575

Andreone, B. J., Lacoste, B., and Gu, C. (2015). Neuronal and vascular interactions. Annu. Rev. Neurosci. 38, 25-46. doi: 10.1146/annurev-neuro-071714-033835

Argente-Arizón, P., Freire-Regatillo, A., Argente, J., and Chowen, J. A. (2015). Role of non-neuronal cells in body weight and appetite control. Front. Endocrinol. 6:42. doi: 10.3389/fendo.2015.00042

Armulik, A., Genové, G., and Betsholtz, C. (2011). Pericytes: developmental, physiological, and pathological perspectives, problems, and promises. Dev. Cell. 21, 193-215. doi: 10.1016/j.devcel.2011.07.001

Armulik, A., Genové, G., Mäe, M., Nisancioglu, M. H., Wallgard, E., Niaudet, C., et al. (2010). Pericytes regulate the blood-brain barrier. Nature 468, 557-556. doi: $10.1038 /$ nature09522

Bady, I., Marty, N., Dallaporta, M., Emery, M., Gyger, J., Tarussio, D., et al. (2006). Evidence from glut2-null mice that glucose is a criticalphysiological regulator of feeding. Diabetes 55, 988-995. doi: 10.2337/diabetes.55.04.06.db05-1386

Balland, E., Dam, J., Langlet, F., Caron, E., Steculorum, S., Messina, A. et al. (2014). Hypothalamic tanycytes are an ERK-gated conduit for leptin into the brain. Cell Metab. 19, 293-301. doi: 10.1016/j.cmet.2013.12.015

Banks, W. A. (2016). From blood-brain barrier to blood-brain interface: new opportunities for CNS drug delivery. Nat. Ver. Drug Discov. 15, 275-292. doi: 10.1038/nrd.2015.21

Banks, W. A., Jaspan, J. B., and Kastin, A. J. (1997). Effect of diabetes mellitus on the permeability of the blood-brain barrier to insulin. Peptides 18, 1577-1584. doi: 10.1016/S0196-9781(97)00238-6

Banks, W. A., Kastin, A. J., Huang, W., Jaspan, J. B., and Maness, L. M. (1996). Leptin enters the brain by a saturable system independent of insulin. Peptides 17, 305-311. doi: 10.1016/0196-9781(96)00025-3

Bauer, H., Sonnleitner, U., Lametschwandtner, A., Steiner, M., Adam, H., and Bauer, H. C. (1995). Ontogenic expression of the erythroid-type glucose transporter (Glut 1) in the telencephalon of the mouse: correlation to the tightening of the blood-brain barrier. Brain Res. Dev. Brain Res. 86, 317-325. doi: 10.1016/0165-3806(95)00044-E

Bell, R. D., Winkler, E. A., Sagare, A. P., Singh, I., LaRue, B., Deane, R., et al. (2010). Pericytes control key neurovascular functions and neuronal phenotype in the adult brain and during brain aging. Neuron 68, 409-427. doi: 10.1016/j.neuron.2010.09.043

Bennett, L., Yang, M., Enikolopov, G., and Iacovitti, L. (2009). Circumventricular organs: a novel site of neural stem cells in the adult brain. Mol. Cell. Neurosci. 41, 337-347. doi: 10.1016/j.mcn.2009.04.007

Ben-Zvi, A., Lacoste, B., Kur, E., Andreone, B. J., Mayshar, Y., and Yan, H. (2014). Mfsd2ais critical for the formation and function of the blood-brain barrier. Nature 22, 507-511. doi: 10.1038/nature13324

Berger, M., Bergers, G., Arnold, B., Hämmerling, G. J., and Ganss, R. (2005). Regulator of G-protein signaling-5 induction in pericytes coincides with active vessel remodeling during neovascularization. Blood 105, 1094-1101. doi: 10.1182/blood-2004-06-2315

Betsholtz, C. (2014). Physiology: double function at the blood-brain barrier. Nature 509, 432-433. doi: 10.1038/nature13339

Blanchette, M., and Daneman, R. (2015). Formation and maintenance of the BBB. Mech. Dev. 138, 8-16. doi: 10.1016/j.mod.2015.07.007

Boado, R. J., and Pardridge, W. M. (1990). The brain-type glucose transporter mRNA is specifically expressed at the blood-brain barrier. Biochem. Biophys. Res. Commun. 166, 174-179. doi: 10.1016/0006-291X(90) 91927-K

Bondjers, C., He, L., Takemoto, M., Norlin, J., Asker, N., Hellström, M., et al. (2006). Microarray analysis of blood microvessels from PDGF-B and PDGFRbeta mutant mice identifies novel markers for brain pericytes. FASEB J. 20, 1703-1705. doi: 10.1096/fj.05-4944fje

Bribair, A., Zhang, T., Wang, Z. M., Messi, M. L., Enikolopov, G. N., Mintz, A., et al. (2013). Skeletal muscle pericyte subtypes differ in their differentiation potential. Stem Cell Res. 10, 67-84. doi: 10.1016/j.scr.2012.09.003
Cabezas, R., Ávila, M., Gonzalez, J., El-Bachá, S., and Báez, E., García-Segura, L. M. (2014). Astrocytic modulation of blood brain barrier: perspectives on Parkinson's disease. Front. Cell. Neurosci. 8:211. doi: 10.3389/fncel.2014.00211

Campbell, J. N., Macosko, E. Z., Fenselau, H., Pers, T. H., Lyubetskaya, A., Tenen, D., et al. (2017). A molecular census of arcuate hypothalamus and median eminence cell types. Nat. Neurosci. 20, 484-496. doi: 10.1038/nn.4495

Carmeliet, P., Ferreira, V., Breier, G., Pollefeyt, S., Kieckens, L., Gersenstein, M., et al. (1996). Abnormal blood vessel development and lethality in embryos lacking a single VEGF allele. Nature 380, 435-439. doi: 10.1038/380435a0

Cashion, M. F., Banks, W. A., and Kastin, A. J. (1996). Sequestration of centrally administered insulin by the brain: effects of starvation, aluminum, and TNFalpha. Horm. Behav. 30, 280-286. doi: 10.1006/hbeh.1996.0034

Cavadas, C., Aveleira, C. A., Souza, G. F., and Velloso, L. A. (2016). The pathophysiology of defective proteostasis in the hypothalamus - from obesity to ageing. Nat. Rev. Endocrinol. 12, 723-733. doi: 10.1038/nrendo.2016.107

Chow, B. W., and Gu, C. (2015). The molecular constituents of the blood-brain barrier. Trends Neurosci. 38, 598-608. doi: 10.1016/j.tins.2015.08.003

Chowen, J. A., Argente-Arizón, P., Freire-Regatillo, A., Frago, L. M., Horvath, T. L., and Argente, J. (2016). The role of astrocytes in the hypothalamic response and adaptation to metabolic signals. Prog Neurobiol. 144, 68-87. doi: 10.1016/j.pneurobio.2016.03.001

Collden, G., Balland, E., Parkash, J., Caron, E., Langlet, F., Prevot, V., et al. (2014). Neonatal overnutrition causes early alterations in the central response to peripheral ghrelin. Mol. Metab. 4, 15-24. doi: 10.1016/j.molmet.2014.10.003

Correale, J., and Villa, A. (2009). Cellular elements of the blood-brain barrier. Neurochem. Res. 34, 2067-2077. doi: 10.1007/s11064-009-0081-y

Cullen, M., Elzarrad, M. K., Seaman, S., Zudaire, E., Stevens, J., Yang, M. Y., et al. (2011). GPR124, an orphan G protein-coupled receptor, is required for CNSspecific vascularization and establishment of the blood-brain-barrier. Proc. Natl. Acad. Sci. U.S.A. 108, 5759-5764. doi: 10.1073/pnas.1017192108

da Fonseca, A. C., Matias, D., Garcia, C., Amaral, R., Geraldo, L. H., Freitas, C., et al. (2014). The impact of microglial activation on blood-brain barrier in brain diseases. Front. Cell. Neurosci. 8:362. doi: 10.3389/fncel.2014.00362

Daneman, R., Agalliu, D., Zhou, L., Kuhnert, F., Kuo, C. J., and Barres, B. A. (2009). Wnt/beta-catenin signaling is required for CNS, but not non-CNS, angiogenesis. Proc. Natl. Acad. Sci. U.S.A. 106, 641-646. doi: $10.1073 /$ pnas.0805165106

Daneman, R., and Prat, A. (2015). The blood-brain barrier. Cold Spring Harb. Perspect. Biol. 7:a020412. doi: 10.1101/cshperspect.a020412

Daneman, R., Zhou, L., Agalliu, D., Cahoy, J. D., Kaushal, A., and Barres, B. A. (2010a). The mouse blood-brain barrier transcriptome: A new resource for understanding the development and function of brain endothelial cells. PLoS ONE 5:e13741. doi: 10.1371/journal.pone.0013741

Daneman, R., Zhou, L., Kebede, A. A., and Barres, B. A. (2010b). Pericytes are required for blood-brain barrier integrity during embryogenesis. Nature 468, 562-566. doi: 10.1038/nature09513

Dejana, E., and Vestweber, D. (2013). The role of VE-cadherin in vascular morphogenesis and permeability control. Prog. Mol. Biol. Transl. Sci.116, 119-144. doi: 10.1016/B978-0-12-394311-8.00006-6

de Vries, H. E., Kooij, G., Frenkel, D., Georgopoulos, S., Monsonego, A., and Janigro, D. (2012). Inflammatory events at blood-brain barrier in neuroinflammatory and neurodegenerative disorders: implications for clinical disease. Epilepsia 6, 45-52. doi: 10.1111/j.1528-1167.2012.03702.x

Dore-Duffy, P., and Cleary, K. (2011). Morphology and properties of pericytes. Methods Mol. Biol. 686, 49-68. doi: 10.1007/978-1-60761-938-3_2

Dziegielewska, K. M., Evans, C. A., Malinowska, D. H., Møllgård, K., Reynolds, J. M., Reynolds, M. L., et al. (1979). Studies of the development of brain barrier systems to lipid insoluble molecules in fetal sheep. J. Physiol. 292, 207-231. doi: 10.1113/jphysiol.1979.sp012847

Eberth, C. J. (1871). Handbuch der Lehre von der Gewegen des Menschen und der Tiere, Vol. 1. Leipzig: Engelmann.

Ehrlich, P. (1885). Das Sauerstoff-Bedürfniss des Organismus: eine Farbenanalytische Studie. Berlin: Hirschwald.

Engelhardt, B., and Liebner, S. (2014). Novel insights into the development and maintenance of the blood-brain barrier. Cell Tissue Res. 355, 687-699. doi: 10.1007/s00441-014-1811-2

Fantin, A., Vieira, J. M., Gestri, G., Denti, L., Schwarz, Q., Prykhozhij, S., et al. (2010). Tissue macrophages act as cellular chaperones for vascular anastomosis 
downstream of VEGF-mediated endothelial tip cell induction. Blood 116, 829-840. doi: 10.1182/blood-2009-12-257832

Farrell, C. L., and Pardridge, W. M. (1991). Blood-brain barrier glucose transporter is asym-metrically distributed on brain capillary endothelial lumenal and ablumenalmembranes: an electron microscopic immunogold study. Proc. Natl. Acad. Sci. U.S.A. 88, 5779-5783. doi: 10.1073/pnas.88. 13.5779

Fenselau, H., Campbell, J. N., Verstegen, A. M., Madara, J. C., Xu, J., Shah, B. P., et al. (2017). A rapidly acting glutamatergic ARC $\rightarrow$ PVH satiety circuit postsynaptically regulated by $\alpha-\mathrm{MSH}$. Nat. Neurosci. 20, 42-51. doi: $10.1038 / \mathrm{nn} .4442$

Fernández-Klett, F., Offenhauser, N., Dirnagl, U., Priller, J., and Lindauer, U. (2010). Pericytes in capillaries are contractile in vivo, but arterioles mediate functional hyperemia in the mouse brain. Proc. Natl. Acad. Sci. USA, 107, 22290-22295. doi: 10.1073/pnas.1011321108

Frayling, C., Britton, R., and Dale, N. (2011). ATP-mediated glucosensing by hypothalamic tanycytes. J. Physiol. 589(Pt 9), 2275-2286. doi: 10.1113/jphysiol.2010.202051

Ganong, W. F. (2000). Circumventricular organs: definition and role in the regulation of endocrine and autonomic function. Clin. Exp. Pharmacol. Physiol. 27, 422-427. doi: 10.1046/j.1440-1681.2000.03259.x

Goldmann, E. E. (1909). Dieäussere und innere Sekretion des gesunden und kranken Organismus im Lichte der 'vitalen Färbung.' Beiträg Klinische Chirurgie 64, 192-265.

Goldmann, E. E. (1913). Vitalfärbung am Zentralnervensyatem. Beitrag zur Physio-Pathologie dês plexus chorioideus und der Hirnhäute. Abh preuss, Akad Wiss Phys-Math Kl 1, 1-60.

Haan, N., Goodman, T., Najdi-Samiei, A., Stratford, C. M., Rice, R., El Agha, E., et al. (2013). Fgf10-expressing tanycytes add new neurons to the appetite/energy-balance regulating centers of the postnatal and adult hypothalamus. J. Neurosci. 33, 6170-6180. doi: 10.1523/JNEUROSCI.2437-12.2013

Hagan, N., and Ben-Zvi, A. (2015). The molecular, cellular, and morphological components of blood-brain barrier development during embryogenesis. Semin. Cell Biol. 38, 7-15. doi: 10.1016/j.semcdb.2014. 12.006

Halilagic, A., Ribes, V., Ghyselinck, N. B., Zile, M. H., Dollé, P., and Studer, M. (2007). Retinoids control anterior and dorsal properties in the developing forebrain. Dev Biol. 303, 362-375. doi: 10.1016/j.ydbio.2006. 11.021

Hall, C. N., Reynell, C., Gesslein, B., Hamilton, N. B., Mishra, A., Sutherland, B. A., et al. (2014). Capillary pericytes regulate cerebral blood flow in health and disease. Nature 508, 55-60. doi: 10.1038/nature 13165

Havrankova, J., Brownstein, M., and Roth, J. (1981). Insulin and insulin receptors in rodent brain. Diabetologia 20, 268-273. doi: 10.1007/BF00 254492

Hawkins, R. A., O'Kane, R. L., Simpson, I. A., and Viña, J. R. (2006). Structure of the blood-brain barrier and its role in the transport of amino acids. J. Nutr. 36, 218S-226S.

Hellstrom, M., Gerhardt, H., Kalén, M., Li, X., Eriksson, U., Wolburg, H., et al. (2001). Lack of pericytes leads to endothelial hyperplasia and abnormal vascular morphogenesis. J. Cell Biol. 153, 543-553. doi: 10.1083/jcb.153.3.543

Hellstrom, M., Kalen, M., Lindahl, P., Abramsson, A., and Betsholtz, C. (1999). Role of PDGF-B and PDGFR- $\beta$ in recruitment of vascular smooth muscle cells and pericytes during embryonic blood vessel formation in the mouse. Development 126, 3047-3055.

Hill, R. A., Tong, L., Yuan, P., Murikinati, S., Gupta, S., and Grutzendler, J. (2015). Regional blood flow in the normal and ischemic brain is controlled by arteriolar smooth muscle cell contractility and not by capillary pericytes. Neuron 87 , 95-110. doi: 10.1016/j.neuron.2015.06.001

Hofmann, K., Lamberz, C., Piotrowitz, K., Offermann, N., But, D., Scheller, A., et al. (2017). Tanycytes and a differential fatty acid metabolism in the hypothalamus. Glia 65, 231-249. doi: 10.1002/glia.23088

Holly, J., and Perks, C. (2006). The role of insulin-like growth factor binding proteins. Neuroendocrin 83, 154-160. doi: 10.1159/000095523

Janzer, R. C., and Raff, M. C. (1987). Astrocytes induce blood-brain barrier properties in endothelial cells. Nature 325, 253-257. doi: 10.1038/325 $253 \mathrm{a} 0$
Kastin, A. J., and Akerstrom, V. (2000). Fasting, but not adrenalectomy, reduces transport of leptin into the brain. Peptides 21, 679-682. doi: 10.1016/S0196-9781(00)00195-9

Kastin, A. J., Akerstrom, V., and Hackler, L. (2001). Food deprivation decreases blood galanin-like peptide and its rapid entry into the brain. Neuroendocrinology 74, 423-432. doi: 10.1159/000054708

Keaney, J., and Campbell, M. (2015). The dynamic blood-brain barrier. FEBS J. 282, 4067-4079. doi: 10.1111/febs.13412

Keller, A. (2013). Breaking and building the wall: the biology of the blood-brain barrier in health and disease. Swiss Med. Wkly. 143, 1-9. doi: 10.4414/smw.2013.13892

Kim, D. W., Glendining, K. A., Grattan, D. R., and Jasoni, C. L. (2016). Maternal obesity in the mouse compromises the blood-brain barrier in the arcuate nucleus of offspring. Endocrinology 157, 2229-2242. doi: 10.1210/en.2016-1014

Kim, J. G., Suyama, S., Koch, M., Jin, S., Argente-Arizon, P., Argente, J., et al. (2014). Leptin signaling in astrocytes regulates hypothalamic neuronal circuits and feeding. Nat. Neurosci. 17, 908-910. doi: 10.1038/ nn. 3725

Kuhnert, F., Mancuso, M. R., Shamloo, A., Wang, H. T., Choksi, V., Florek, M., et al. (2010). Essential regulation of CNS angiogenesis by the orphan G proteincoupled receptor GPR124. Science 330, 985-989. doi: 10.1126/science.11 96554

Lam, B. Y. H., Cimino, I., Polex-Wolf, J., Kohnke, S. N., Rimmington, D., Iyemere, V., et al. (2017). Heterogeneity of hypothalamic Pro-opiomelanocortinexpressing neurons revealed by single-cell RNA sequencing. Mol. Met. 6, 1-10. doi: 10.1016/j.molmet.2017.02.007

Lam, T. K., Schwartz, G. J., and Rossetti, L. (2005). Hypothalamic sensing of fatty acids. Nat. Neurosci. 8, 579-584. doi: 10.1038/nn1456

Langlet, F., Levin, B. E., Luquet, S., Mazzone, M., Messina, A., et al. (2013a). Tanycytic VEGF-A boosts blood-hypothalamus barrier plasticity and access of metabolic signals to the arcuate nucleus in response to fasting. Cell Metab. 17, 607-617. doi: 10.1016/j.cmet.2013.03.004

Langlet, F., Mullier, A., Bouret, S. G., Prevot, V., and Dehouck, B. (2013b). Tanycyte-like cells form a blood-cerebrospinal fluid barrier in the circumventricular organs of the mouse brain. J. Comp. Neurol. 21, 3389-3405. doi: $10.1002 /$ cne. 23355

Lee, D. A., Bedont, J. L., Pak, T., Wang, H., Song, J., Miranda-Angulo, A., et al. (2012). Tanycytes of the hypothalamic median eminence form a diet-responsive neurogenic niche. Nat. Neurosci. 15, 700-702. doi: 10.1038/ nn.3079

Lee, S. W., Kim, W. J., Choi, Y. K., Song, H. S., Son, M. J., et al. (2003). SSeCKS regulates angiogenesis and tight junction formation in blood-brain barrier. Nat. Med. 9, 900-906. doi: 10.1038/nm889

Lewandowsky, M. (1900). Zur Lehre von der Cerebrospinalflüssgkeit. Z. Clin. Med. $40,480-494$

Lichtensteiger, W., Richards, J. G., and Kopp, H. G. (1978). Changes in the distribution of non-neuronal elements in rat median eminence and in anterior pituitary hormone secretion after activation of tuberoinfundibular dopamine neurones by brain stimulation or nicotine. Brain Res. 157, 73-88. doi: 10.1016/0006-8993(78)90997-6

Liebner, S., Corada, M., Bangsow, T., Babbage, J., Taddei, A., Czupalla, C. J., et al. (2008). Wnt/beta-catenin signaling controls development of the blood-brain barrier. J. Cell Biol. 183, 409-417. doi: 10.1083/jcb.2008 06024

Lindahl, P., Johansson, B. R., Levéen, P., and Betsholtz, C. (1997). Pericyte loss and microaneurysm formation in PDGF-B-deficient mice. Science 277, 242-245. doi: $10.1126 /$ science.277.5323.242

Lindblom, P., Gerhardt, H., Liebner, S., Abramsson, A., Hellström, M., Bäckström, G., et al. (2003). Endothelial PDGF-B retention is required for proper investment of pericytes in the microvessel wall. Genes Dev. 17, 1835-1840. doi: 10.1101/gad.266803

Luissint, A. C., Artus, C., Glacial, F., Ganeshamoorthy, K., and Couraud, P. O. (2012). Tight junctions at the blood brain barrier: physiological architecture and disease-associated dysregulation. Fluids Barriers CNS 9:23. doi: $10.1186 / 2045-8118-9-23$

Lull, M. E., and Block, M. L. (2010). Microglial activation and chronic neurodegeneration. Neurotherapeutics 4, 354-365. doi: $10.1016 /$ j.nurt.2010.05.014 
Marty, N., Dallaporta, M., Foretz, M., Emery, M., Tarussio, D., Bady, I., et al. (2005). Regulation of glucagon secretion by glucose transporter type 2 (glut2) and astrocytedependent glucose sensors. J Clin. Invest. 115, 3545-3553. doi: 10.1172/JCI26309

Millis, S. J., Cowin, A. J., and Kaur, P. (2013). Pericytes, mesenchymal stem cells and the wound healing process. Cells. 2, 621-634 doi: 10.3390/cells2030621

Mitchell, R. W., and Hatch, G. M. (2011). Fatty acid transport into the brain: of fatty acid fables and lipid tails. Prostaglandins Leukot. Essent. Fatty Acids. 85, 293-302. doi: 10.1016/j.plefa.2011.04.007

Mizee, M. R., Wooldrik, D., Lakeman, K. A., van het Hof, B., Drexhage, J. A., Geerts, D., et al. (2013). Retinoic acid induces blood-brain barrier development. J. Neurosci 33, 1660-1671. doi: 10.1523/JNEUROSCI.133812.2013

Mullier, A., Bouret, S. G., Prevot, V., and Dehouck, B. (2010). Differential distribution of tight junction proteins suggests a role for tanycytes in bloodhypothalamus barrier regulation in the adult mouse brain. J. Comp. Neurol. 518, 943-962. doi: 10.1002/cne.22273

Nayak, D., Roth, T. L., and McGavern, D. B. (2014). Microglia development and function. Annu. Rev. Immunol. 32, 367-402. doi: 10.1146/annurev-immunol-032713-120240

Nishioku, T., Matsumoto, J., Dohgu, S., Sumi, N., Miyao, K., Takata, F., et al. (2010). Tumor necrosis factor-alpha mediates the blood-brain barrier dysfunction induced by activated microglia in mouse brain microvascular endothelial cells. J. Pharmacol. Sci. 112, 251-254. doi: 10.1254/jphs.09292SC

Obermeier, B., Daneman, R., and Ransohoff, R. M. (2013). Development, maintenance and disruption of the blood-brain barrier. Nat. Med. 19, 1584-1596. doi: 10.1038/nm.3407

Obici, S., and Rossetti, L. (2003). Minireview: nutrient sensing and the regulation of insulin action and energy balance. Endocrinology144, 5172-5178. doi: 10.1210/en.2003-0999

Olsson, A. K., Dimberg, A., Kreuger, J., and Claesson-Welsh, L. (2006). VEGF receptor signalling-in control of vascular function. Nat. Rev. Mol. Cell Biol. 7, 359-371. doi: 10.1038/nrm1911

Pam, W., Banks, W. A., Kennedy, M. K., Guiterrez, E. G., and Kastin, A. J. (1996). Differential permeability of the BBB in acute EAE: enhanced transport of TNT-alpha. Am. J. Physiol. 271, E636-E642.

Pardridge, W. M., Boado, R. J., and Farrell, C. R. (1990). Brain-type glucose transporter (GLUT-1) is selectively localized to the blood-brain barrier. Studies with quantitative western blotting and in situ hybridization. J. Biol Chem. 265, 18035-18040.

Peppiatt, C. M., Howarth, C., Mobbs, P., and Attwell, D. (2006). Bidirectional control of CNS capillary diameter by pericytes. Nature 443, 700-704. doi: 10.1038/nature05193

Potente, M., Gerhardt, H., and Carmeliet, P. (2011). Basic and therapeutic aspects of angiogenesis. Cell 146, 873-887. doi: 10.1016/j.cell.2011.08.039

Raab, S., Beck, H., Gaumann, A., Yüce, A., Gerber, H. B., Plate, K., et al. (2004). Impaired brain angiogenesis and neuronal apoptosis induced by conditional homozygous inactivation of vascular endothelial growth factor. Thromb. Haemost. 91, 595-605. doi: 10.1160/th03-09-0582

Reese, T. S., and Karnovsky, M. J. (1967). Fine structural localization of a blood-brain barrier to exogenous peroxidase. J. Cell Biol. 34, 207-217. doi: $10.1083 /$ jcb.34.1.207

Ribatti, D., Nico, B., Crivellato, E., and Artico, M. (2006).Development of the blood-brain barrier: a historical point of view. Anat. Rec. B New Anat. 289B, 3-8. doi: 10.1002/ar.b.20087

Risau, W., Hallmann, R., and Albrecht, U. (1986). Differentiation dependent expression of proteins in brain endothelium during development of the bloodbrain barrier. Dev. Biol. 117, 537-545. doi: 10.1016/0012-1606(86)90321-0

Rodríguez, E. M., Blázquez, J. L., and Guerra, M. (2010). The design of barriers in the hypothalamus allows the median eminence and the arcuate nucleus to enjoy private milieus: the former opens to the portal blood and the latter to the cerebrospinal fluid. Peptides 31, 757-776. doi: 10.1016/j.peptides.2010. 01.003

Rouget, C. (1873). Memoire sur le developpement, la structures et les proprietes des capillaires sanguins et lymphatiques. Archs. Physiol. Norm. Pathol. 5, 603-633.

Rustenhoven, J., Jansson, D., Smyth, L. C., and Dragunow, M. (2016). Brain pericytes as mediators of neuroinflammation. Trends Pharmacol. Sci. 38, 291-304. doi: 10.1016/j.tips.2016.12.001
Saijo, K., and Glass, C. K. (2011). Microglial cell origin and phenotypes in health and disease. Nat. Rev. Immunol. 11, 775-787. doi: 10.1038/nri3086

Saunders, N. R., Daneman, R., Dziegielewska, K. M., and Liddelow, S. A. (2013). Transporters of the blood-brain and blood-CSF interfaces in development and in the adult. Mol. Aspects Med. 34, 742-752. doi: 10.1016/j.mam.2012.11.006

Saunders, N. R., Liddelow, S. A., and Dziegielewska, K. M. (2012). Barrier mechanisms in the developing brain. Front. Pharmacol. 3:46. doi: 10.3389/fphar.2012.00046

Shalaby, F., Rossant, J., Yamaguchi, T. P., Gersenstein, M., Wu, X. F., Breitman, M. L., et al. (1995). Failure of blood-island formation and vasculogenesis in Flk-1-deficient mice. Nature 376, 62-66. doi: 10.1038/376062a0

Shepro, D., and Morel, N. M. (1993). Pericyte physiology. FASEB J. 7, 1031-1038.

Siegenthaler, J. A., Sohet, F., and Daneman, R. (2013). 'Sealing off the CNS': cellular and molecular regulation of blood-brain barriergenesis. Curr. Opin. Neurobiol. 23, 1057-1064. doi: 10.1016/j.conb.2013.06.006

Sofroniew, M. V., and Vinters, H. V. (2010). Astrocytes: biology and pathology Acta Neuropathol. 119, 7-35. doi: 10.1007/s00401-009-0619-8

Stenman, J. M., Rajagopal, J., Carroll, T. J., Ishibashi, M., McMahon, J., and McMahon, A. P. (2008). Canonical Wnt signaling regulates organ-specific assembly and differentiation of CNS vasculature. Science 322, 1247-1250. doi: 10.1126/science.1164594

Stolarczyk, E., Guissard, C., Michau, A., Even, P. C., Grosfeld, A., Serradas, P., et al. (2010). Detection of extracellular glucose by GLUT2 contributes to hypothalamic control of food intake. Am J Physiol Endocrinol. Metab. 298, E1078-E1087.doi: 10.1152/ajpendo.00737.2009

Sumi, N., Nishioku, T., Takata, F., Matsumoto, J., Watanabe, T., Shuto, H., et al. (2010). Lipopolysaccharide-activated microglia induce dysfunction of the blood-brain barrier in rat microvascular endothelial cells co-cultured with microglia. Cell. Mol. Neurobiol. 30, 247-253. doi: 10.1007/s10571-0099446-7

Szathmari, A., Champier, J., Ghersi-Egea, J. F., Jouvet, A., Watrin, C., Wierinckx, A., et al (2013). Molecular characterization of circumventricular organs and third ventricle ependyma in the rat: potential markers for periventricular tumors. Neuropathology 33, 17-29. doi: 10.1111/j.1440-1789.2012.01321.x

Tallquist, M. D., French, W. J., and Soriano, P. (2003). Additive effects of PDGF receptor beta signaling pathways in vascular smooth muscle cell development. PLoS Biol. 1:E52. doi: 10.1371/journal.pbio.00 00052

Tam, S. J., Richmond, D. L., Kaminker, J. S., Modrusan, Z., Martin-McNulty, B., Cao, T. C., et al. (2012). Death receptors DR6 and TROY regulate brain vascular development. Dev. Cell 22, 403-417. doi: 10.1016/j.devcel.2011. 11.018

Theis, M., Sohl, G., Eiberger, J., and Willecke, K. (2005). Emerging complexities in identity and function of glial connexins. Trends Neurosci. 28, 188-195. doi: 10.1016/j.tins.2005.02.006

Tietz, S., and Engelhardt, B. (2015). Brain barriers: crosstalk between complex tight junctions and adherens junctions. J. Cell Biol. 209, 493-506. doi: $10.1083 /$ jcb.201412147

Trost, A., Lange, S., Schroedl, F., Bruckner, D., Motloch, A. K., Bogner, B. et al. (2016). Brain and retinal pericytes: origin, function and role. Front. Cell. Neurosci. 4:20. doi: 10.3389/fncel.2016.00020

Vallet, P. G., Charnay, Y., Boura, C., and Kiss, J. Z. (1991). Colocalization of delta sleep inducing peptide and luteinizing hormone releasing hormone in neurosecretory vesicles in rat median eminence. Neuroendocrinology 53, 103-106. doi: 10.1159/000125705

Velloso, L. A., and Schwartz, M. W. (2011). Altered hypothalamic function in diet-induced obesity. Int. J. Obes. 35, 1455-1465. doi: 10.1038/ijo.2011.56

Wagner, H. J., and Pilgrim, C. (1974). Extracellular and transcellular transport of horseradish peroxidase (HRP) through the hypothalamic tanycyte ependyma. Cell Tissue Res. 152, 477-491. doi: 10.1007/BF00218933

Wang, Y., Rattner, A., Zhou, Y., Williams, J., Smallwood, P. M., and Nathans, J. (2012). Norrin/Frizzled4 signaling in retinal vascular development and bloodbrain barrier plasticity. Cell 151, 1332-1344. doi: 10.1016/j.cell.2012.10.042

Weindl, A., and Joynt, R. J. (1973). Barrier properties of the subcommissural organ. Arch. Neurol. 29, 16-22.

Winkler, E. A., Bell, R., and Zlokovic, B. V. (2011). Central nervous system pericytes in health and disease. Nat. Neurosci. 14, 1398-1405. doi: $10.1038 / \mathrm{nn} .2946$ 
Woods, S. C., and Porte, D. Jr. (1977). Relationship between plasma and cerebrospinal fluid insulin levels of dogs. Am J. Physiol. 233, E331-E334.

Wosik, K., Cayrol, R., Dodelet-Devillers, A., Berthelet, F., Bernard, M., Moumdjian, R., et al. (2007). Angiotensin II controls occludin function and is required for blood-brain barrier maintenance: relevance to multiple sclerosis. J. Neurosci. 27, 9032-9042. doi: 10.1523/JNEUROSCI.2088-07.2007

Xiao, G., and Gan, L. S. (2013). Receptor-mediated endocytosis and brain delivery of therapeutic biologics. Int. J. Cell Biol. 2013:703545. doi: 10.1155/2013/703545

Zenker, D., Begley, D., Bratzke, H., Rübsamen-Waigmann, H., and von Briesen, H. (2003). Human blood-derived macrophages enhance barrier function of cultured primary bovine and human brain capillary endothelial cells. J. Physiol. 551(Pt 3), 1023-1032. doi: 10.1113/jphysiol.2003.045880

Zhang, X., and van den Pol, N. A. (2016). Hypothalamic arcuate nucleus tyrosine hydroxylase neurons play orexigenic role in energy homeostasis. Nat. Neurosci. 19, 1341-1347. doi: 10.1038/nn.4372

Zhang, Y., Proenca, R., Maffei, M., Barone, M., Leopold, L., and Friedman, J. M. (1994). Positional cloning of the mouse obese gene and its human homologue. Nature 372, 425-432.

Zhao, Z., Nelson, A. R., Betsholtz, C., and Zlokovic, B. V. (2015). Establishment and dysfunction of the blood-brain barrier. Cell 163, 1064-1078. doi: $10.1016 /$ j.cell.2015.10.067
Zhou, Y., and Nathans, J. (2014). Gpr124 controls CNS angiogenesis and blood-brain barrier integrity by promoting ligand-specific canonical Wnt signaling. Dev. Cell 31, 248-256. doi: 10.1016/j.devcel.2014. 08.018

Zimmermann, K. W. (1923). Der feinere bau der blutcapillares. Z. Anat. Entwicklungsgesch. 68, 3-109. doi: 10.1007/978-3-642-92456-9

Zlokovic, B. V. (2008). The blood-brain barrier in health and chronic neurodegenerative disorders. Neuron 57, 178-201. doi: 10.1016/j.neuron.2008. 01.003

Conflict of Interest Statement: The authors declare that the research was conducted in the absence of any commercial or financial relationships that could be construed as a potential conflict of interest.

Copyright (C) 2017 Haddad-Tóvolli, Dragano, Ramalho and Velloso. This is an openaccess article distributed under the terms of the Creative Commons Attribution License (CC BY). The use, distribution or reproduction in other forums is permitted, provided the original author(s) or licensor are credited and that the original publication in this journal is cited, in accordance with accepted academic practice. No use, distribution or reproduction is permitted which does not comply with these terms. 